\title{
A FANTASIA DA CRIANÇA NA EDUCAÇÃO INFANTIL: EM BUSCA DE NOVOS CAMINHOS E DESCOBERTAS
}

Tony Aparecido Moreira, Denise Watanabe, José Milton de Lima, Márcia Regina Canhoto de Lima

FCT/UNESP - Departamento de Educação, Campus de Presidente Prudente - SP. Agência financiadora: PPGE/CAPES. E-mail: tony.educ@gmail.com

\section{RESUMO}

O presente estudo, vinculado ao Programa de Pós-Graduação em Educação da FCT/UNESP de Presidente Prudente parte de resultados de pesquisas anteriores que identificaram que a fantasia da criança não é, ainda, compreendida e valorizada de forma efetiva no contexto da Educação Infantil. O estudo está fundamentado sobre os teóricos da Sociologia da Infância e outros autores que pesquisam sobre a imaginação das crianças, tem o objetivo de ampliar a compreensão da fantasia da criança e encontrar caminhos para seu desenvolvimento no contexto escolar. A investigação é de natureza qualitativa e se apóia no método da investigação-ação, que tem natureza empírica voltada a transformação da realidade. Entre os resultados já alcançados, destacamos repercussões na abordagem das professoras, diminuição da evasão de crianças e maior participação delas durante a rotina escolar por meio de expressões imaginativas e criativas que rendem um novo sentido às práticas educativas.

Palavras-chave: Fantasia; Criança; Educação Infantil; Sociologia da Infância; Culturas da Infância.

\section{INTRODUÇÃO E OBJETIVO}

As crianças nunca deixaram de estar presentes na história das sociedades, mas as concepções em relação a infância foram distintas ao longo dos tempos. Àries (2011) é considerado como o principal autor em relatar a desconsideração em relação a criança nos períodos medievais, mesmo sendo questionado por alguns autores, sua obra representa um divisor de águas na história da infância.

A Sociologia muito tempo se limitou a considerar a criança a partir de instituições, vista dentro da família e da escola, sem contemplar a infância em particular. Nesse sentido, a socialização da criança estava fundamentada na perspectiva de Durkheim (1973), como um indivíduo que precisa estar integrado a sociedade para poder seguir a ordem social.

Mesmo que outras áreas do conhecimento liderassem estudos em relação a criança, era necessário que a infância fosse compreendida sob um novo pensamento social, da socialização não como resultado da ação das instituições, mas como um processo individual e social (MULLER; HASSEN, 2009), e a infância como uma categoria de sujeitos concretos da sociedade sob a qual fossem produzidos saberes não apenas limitados a como ensinar, controlar ou cuidar na perspectiva adultocêntrica ou naturalística, mas, especialmente em entender o ator social criança 
a partir de suas realidades e não por conceitos reproduzidos de forma vertical. Como Sirota (2001, p.28), expressa: "[...] trata-se de compreender aquilo que criança faz de si e aquilo que se faz dela, e não simplesmente aquilo que as instituições inventam para ela".

Dentro da sociologia as primeiras tentativas de construir um novo campo de estudo ocorreram na década de 30 do século XX com Marcel Mauss (2010), mas a visão centrada no adulto impedia o surgimento de uma concepção que questionasse essa realidade e barrou a consolidação de uma nova natureza teórica no meio acadêmico que representava um primordial caminho para expandir a vertente.

Décadas mais tarde, nos anos 80, pesquisadores de diferentes partes do mundo começaram a apresentar estudos sobre a criança na perspectiva de um sujeito social e construtor de cultura, nesse período, ocorria o que Prout (2004) considera como uma aparente crise da infância a nível cultural, representada principalmente pelos trabalhos que anunciaram o desaparecimento da infância. Segundo o autor, as velhas idéias de infância já não eram mais adequadas, o nascimento da Sociologia da Infância marca um momento para novas idéias, libertadas da lógica adultocêntrica e da hegemonia psicologizante.

O que percebemos é que há um grande distanciamento entre os avanços já visualizados a nível teórico e o que ocorre nas instituições de Educação Infantil. Se tratando do contexto investigado, as "novas idéias" ainda não alcançaram o patamar de novas atitudes. Sobrevive um conceito comum de infância como um evento natural e universal, etapa da vida associada a irracionalidade e imaturidade.

Tendo em vista tantos séculos em que as crianças foram consideradas como adultos em miniatura, a transformação dos olhares não acontecerá de forma tranqüila. A escola resguarda esses cidadãos do futuro e corresponde tanto a um dispositivo de proteção quanto de subordinação a um regime de autoridade paternalista (FERREIRA; SARMENTO, 2008). Torna-se urgente enfrentar a lógica da socialização vertical, da inculcação de valores na criança, enxergada como um receptáculo passivo (DELGADO; MULLER, 2005). Como expressa Prout (2004, p.03): [...] as velhas idéias de infância não parecem mais adequadas".

Uma velha idéia de infância é representada pela "idade do não", que se refere às impossibilidades do ser criança em relação ao adulto. A criança não fala, não trabalha, não vota, não se casa, não dirige e tantos outros pontos negativos. Mas, para Sarmento (2000, p. 156):

[...] a infância não é a idade da não-fala: todas as crianças desde bebês, têm múltiplas linguagens (gestuais, corporais, plásticas e verbais) por que se expressam. A infância não é a idade da não-razão: para além da 
racionalidade técnico-instrumental, hegemônica na sociedade industrial, outras racionalidades se constroem, designadamente nas intercções entre crianças, com a incorporação de afectos, da fantasia e da vinculação ao real.

Essa visão de negatividade interpreta as culturas produzidas pelas crianças como um déficit e não como competências infantis. O autor (2003), entende que: "[...] é da ordem da diferença e não do déficit que se trata". Se as culturas da infância fossem consideradas como competências particulares das crianças, a realidade da Educação Infantil certamente seria outra. Mas, de algum modo, perante a instituição:

[...] a criança morre, enquanto sujeito concreto, com saberes e emoções, aspirações, sentimentos e vontades próprias, para dar lugar ao aprendiz, destinatário da acção adulta, agente de comportamentos prescritos, pelo qual é avaliado, premiado ou sancionado. A escola criou uma relação particular com o saber, uniformizando o modo de aquisição e transmissão do conhecimento, para além de toda a diferença individual, de classe ou de pertença cultural (SARMENTO, 2011, p. 588).

Pelo nascimento do aluno e morte da criança, o brincar, o imaginar, a expressão livre, perdem espaço para a gama de conteúdos enxergados como fundamentais na construção do adulto precoce (MOLLO-BOUVIER, 2005). O fantasiar enquanto linguagem particular, ponte de acesso ao conhecimento de mundo é enxergado como imaturidade, incompletude. Essa postura distancia o adulto do mundo da criança, que está presente no mesmo mundo, mas que o compreende por meio de caminhos outros. Podemos entender que:

Articular o imaginário com o conhecimento e incorporar as culturas da infância na referenciação das condições e possibilidades das aprendizagens - numa palavra, firmar a educação no desvelamento do mundo e na construção do saber pelas crianças, assistidas pelos professores nessa tarefa de que são protagonistas - pode ser também o modo de construir novos espaços educativos que reinventem a escola pública como a casa das crianças, reencontrando a sua vocação primordial, isto é, o lugar onde as crianças se constituem, pela acção cultural, em seres dotados do direito de participação cidadã no espaço colectivo (SARMENTO, 2003).

Em mais de quatro anos de investigação sobre a fantasia da criança em instituições de Educação Infantil do oeste paulista, identificamos o quanto as instituições estão estruturadas com as caricaturas que os adultos fazem de crianças. Os espaços, as atividades nem sempre representam o que faz sentido para elas, mas majoritariamente o que os adultos entendem como significativo, é um convite para "[...] compreender aquilo que a criança faz de si e aquilo que se faz 
dela, e não simplesmente aquilo que as instituições inventam para ela" (SIROTA, 2001, p. 28).

O desafio de conhecer as crianças implicou escutá-las "[...] como algo central para reconhecer e respeitar o seu valor como seres humanos (ROBERTS, 2005, p. 247). Escutar e mergulhar em seus mundos, já que,

"[...] não basta observar a criança de fora, como também não basta prestar-se a seus brinquedos; é preciso penetrar além do círculo mágico que nos separa, em suas preocupações, suas paixões, é preciso viver o brinquedo (BASTIDE, 1979, p. 153).

Nesse processo de mergulho, foi necessário recuar o olhar adulto e objetivo para com as coisas, e nos permitirmos a uma experiência conduzida pelos protagonistas da infância, que seguem um roteiro aberto e ilimitado, construído em ressonância com muitas vozes, vivido de forma intensa e sem hora para terminar. Em meio a diferentes cenas e viagens enxergamos sujeitos concretos com histórias concretas buscando uma conscientização concreta dos adultos para mais bem viverem suas infâncias.

As estórias narradas pelas crianças são cheias de detalhes especiais, elementos trazidos de fora, coisas vividas em casa ou vistas na televisão, o real e a fantasia se misturam para que a brincadeira valha a pena (SARMENTO, 2003). A capacidade de expressar um fato profundamente inusitado não significa que as crianças tenham um pensamento ilógico, elas são capazes de fantasiar tanto sobre as coisas mais coerentes como sobre as mais distantes de nosso entendimento, estão a explorar limites e possibilidades, e essa linguagem se desenvolve por toda a vida humana (HARRIS, 2002).

Para Sarmento (2004), a fantasia representa ainda um instrumento de resistência perante experiências de dor. Através do imaginário, além da criança encontrar refúgios para superar a dureza de acontecimentos, podemos acrescentar que ela utiliza de subterfúgios para viver a infância mesmo dentro dos limites colocados pelos adultos, já que, em muitos momentos por exemplo, enquanto os professores estão a explicar sobre os conteúdos de formas desprovidas de sentido para as crianças, elas utilizam de seus lápis, cadernos ou outros materiais para fugir para um planeta longínquo por meio de uma nave que viaja pelas mais intrigantes galáxias ou navega pelo "mar das histórias" (RUSHDIE, 1991).

Esse estudo, que surgiu a partir de pesquisas anteriores e ainda está em andamento tem o objetivo de ampliar a compreensão da fantasia da criança por meio de um processo de investigaação, e ainda, encontrar caminhos para valorizar o imaginário infantil dentro das abordagens pedagógicas. 


\section{METODOLOGIA}

Esta pesquisa é de natureza qualitativa, foi aprovada pelo Comitê de Ética em Pesquisa pelas vias da Plataforma Brasil, utiliza a metodologia da Investigação-ação para o alcance dos seus objetivos. Define Contreras-Domingo (1994, p.14):

[...] es uma forma de entender la práticta docente segun la cual intentamos mjorar-la sistematicamente, buscando para ello entender mejor cuáles son los contextos y condicionantes de la misma. No es solo uma ayuda para resolver los problemas de la prática, es decir, para descubrir la natuleza problemática de la enseñanza y para, problematizándola, reorientar el sentido de la misma, así como nuestra valoración de lo que ésta debiera ser, a lo que deberia aspirar.

Encontramos no método da investigação-ação a possibilidade de construir um processo de parceria e formação continuada. São realizadas intervenções semanais com oito turmas de crianças, Pré I e II, com idade entre 3 e 5 anos, de duas uma instituição de Educação Infantil do Município de Presidente Prudente - SP e Álvares Machado - SP. Nenhuma criança foi excluída, garantindo ainda, o direito de não participar, tanto às criança como para as professoras.

Nessas intervenções são desenvolvidas atividades lúdicas, brincadeiras e jogos diversos, escolhidos a partir do contexto cultural das crianças e também construídos com elas. Valorizamos ,sobretudo, a criação imaginária, as atividades de fantasia, de construção de roteiros, personagens, brinquedos e cenários. As intervenções ocorrem dentro de um período de 60 minutos, mas, são realizadas constantes discussões com os sujeitos participantes em outros momentos dentro da instituição, fortalecendo a defesa das atividades se tornarem parte das rotinas e serem constantemente retomadas.

As educadoras acompanham as intervenções, compromisso firmado previamente para possibilitar a problematização da prática, sob qual levantamos os aspectos de discordância em relação aos aportes teóricos, intermediando um espaço de discussão e reflexão sobre as práticas desenvolvidas e as concepções que as permeiam.

Para a obtenção dos dados, são utilizadas diferentes formas de coleta, não há um padrão fixo de instrumento, assim como o método possui um caráter multiplicador de dimensões para enxergar o objeto, também entendido como deslocamento temático, da mesma maneira ocorre em relação ao plano de análise, com maior foco nas relações do que nas técnicas.

Os dados são recolhidos por meio das interações com os sujeitos envolvidos, crianças e educadoras. Buscamos a partir das falas e expressões, identificar as possíveis transformações, em 
especial, a qualificação de concepções e práticas pedagógicas das educadoras e do favorecimento da capacidade simbólica e criativa das crianças.

O método investigação-ação, segundo Benavente (1990, p.11), tem em seu centro os processos de inovação e transformação dinamizados por uma intervenção reflexiva, "cientificamente informada e produtiva, geradora de conhecimentos teóricos e operatórios [...]", responde muito bem aos anseios que sustentamos, em especial, pelo fato de que a fantasia não é uma linguagem com valorização garantida no contexto da Educação Infantil, sendo, muitas vezes, nem considerada como uma atividade humana digna de preocupação.

\section{RESULTADOS}

Além de consideráveis mudanças de pensamentos e práticas que ainda estão se alicerçando, em diálogo constante os sujeitos identificaram:

- $\quad$ Avanço gradativo da participação das crianças durante as intervenções, e maior delas participação nas aulas comuns;

- $\quad$ Evolução da criatividade, com apresentação de um maior número de elementos em atividades discursivas, artísticas e expressivas;

- $\quad$ Diminuição de faltas e evasão de crianças;

- $\quad$ Envolvimento dos pais com as atividades e maior participação deles durante as brincadeiras de seus filhos.

\section{DISCUSSÃO}

A opinião das crianças é valorizada durante todo o processo de preparo e realização das intervenções, assim como, na coleta e análise dos dados. Elas deixam explicito o interesse pelas atividades desenvolvidas e reivindicam maior tempo para brincarem e fantasiarem dentro da instituição, por esse fato as professoras e diretoras solicitaram um maior período de intervenção.

A relação com as professoras está cada vez mais estreita e satisfatória, elas decidiram aceitar o desafio e consequentemente foram rompendo com idéias fragmentadas de infância, assim como técnicas de imposição e coerção. Os aportes teóricos auxiliam na justificativa do discurso e as próprias crianças expressam o sentido que as atividades agregam aos seus processos de escolarização e em suas vidas como um todo. 
A metodologia da investigação-ação está respondendo muito bem aos anseios firmados, já que permite um amplo estudo da realidade e uma intima relação de parceria em prol da transformação.

A pesquisa ainda está em andamento, e certamente um número maior de descobertas virão, pois o olhar fantástico e ilimitado da criança, nos faz acreditar em conquistas muito maiores que os alcances imaginados como possíveis.

\section{CONCLUSÃO}

O olhar da criança nos desafia, já que, não se enquadra ao duro imediatismo adulto, é um simulacro de possibilidades, de cores, de vozes, que entre brincadeiras em verdades inteiras dá ao nosso tempo uma esperança de construir um mundo mais agradável, mas cheio de recreios e histórias felizes.

Pesquisar sobre a fantasia da criança é se permitir ao um encontro com o belo e identificar as formas de torná-lo mais visível e valorizado. Esta investigação buscará responder a outros questionamentos sobre o imaginário infantil e levantar meios para tornar os espaços educativos mais compatíveis com os anseios e fantasias infantis. Para isso, não deixaremos de escutar as vozes tão silenciadas e acompanhar as cenas tão ignoradas, pois não saberemos percorrer os caminhos da infância sem que os protagonistas nos mostrem como viajar.

\section{REFERÊNCIAS}

ÀRIES, Philippe. História social da Criança e da Família. 2. Ed. Rio de Janeiro: LTC, 2011. 196 p.

BASTIDE, Roger. Prefácio. In: FERNANDES, Florestan. Folclore e mudança social no Estado de São Paulo. Petrópolis: Vozes, 1979.

BRASIL. Ministério da Educação. Diretrizes Curriculares Nacionais para a Educação Infantil. Brasília: MEC/SEB, 2010.

CONTRERAS-DOMINGO, J. La ivestigación em la acción: como se hace?. Cuadernos de Pedagogia, Barcelona, n.. 224, p. 14-19, abr. 1994.

DURKHEIM, Émile. Sociologia, educação e moral. São Paulo: Melhoramentos, 1973.

DELGADO, Ana Cristina ; MULLER, Fernanda. Sociologia da Infância: pesquisa com crianças. Educação e Sociedade, Campinas, v. 26, n.91, p. 351-360, maio/ago. 2005.

FERREIRA, Manuela; SARMENTO, Manuel Jacinto. Subjetividade e bem-estar das crianças: (in)visibilidade e voz. Revista Eletrônica de Educação, São Carlos, v. 2, n. 2, p. 60-91, nov. 2008. 
HARRIS, P. L. Penser à ce qui aurait pu arriver si. Enfance. Paris, 2002, v. 54, p. 223-239. http://dx.doi.org/10.3917/enf.543.0223

MAUSS, M. Três observações sobre a Sociologia da Infância. Pro-posições, Campinas, 2010, p. 237-244.

MOLLO-BOUVIER, Suzanne. Transformação dos modos de socialização das crianças: uma abordagem sociológica. Educação e Sociedade, Campinas, v. 26, n. 91, p. 391-40, maio/ago. 2005.

MULLER, F. ; HASSEN, M. N. A. A infância pesquisada. Psicologia USP, São Paulo, n. 20, p.465-480, jul/set. 2009.

PROUT, A. Reconsiderar a nova sociologia da infância. Braga: Universidade do Minho; 2004.

ROBERTS, Helen. Ouvindo as crianças: e Escutando-as. In: CHRISTENSEN, Pia; JAMES, Alisson. Investigação com crianças. Porto: Escola Superior de Educação de Paula Frassinetti, 2005, 285 p.

RUSHDIE, Salman. Haroun e mar de histórias. São Paulo: Paulicéia, 1991. 189 p.

SARMENTO, Manoel Jacinto. Sociologia da infância: correntes, problemáticas e controvérsias. Cadernos do Noroeste, Porto, vol. 13. 2000. p. 145-164.

SARMENTO, Manoel Jacinto; CERISARA, Ana Beatriz. Crianças e miúdos: perspectivas sociopedagogicas da infância e educação. Porto: ASA, 2004.

SARMENTO, Manoel Jacinto. A Reinvenção do Ofício de Criança e Aluno. Atos de Pesquisa em Educação, v. 6, n. 3, p. 581-602, set./dez. 2011.

SIROTA, R. Emergência de uma sociologia da infância: evolução do objeto e do olhar. Cadernos de pesquisa, São Paulo, n. 112, mar/ 2001. 